Liliana Fracasso*, Sandra C. Mesa García**

\title{
Valorar lo patrimoniable: hábitat popular y patrimonio cultural ${ }^{1}$
}

\author{
Valuing the 'heritageable': popular habitat and cultural \\ heritage \\ Cómo citar:
}

Fracasso, L., \& Mesa, S. (2019). Valorar lo patrimoniable: hábitat popular y patrimonio cultural. Designia, $6(2), 85-115$.

\begin{abstract}
${ }^{1}$ El artículo es resultado del proyecto de investigación "Hábitat popular y creación artística: elaboración de un dispositivo para el análisis de lo patrimoniable en área de borde urbano" financiado por la Universidad Antonio Nariño, Bogotá.

*Profesora Asociada e investigadora de la Facultad de Artes de la Universidad Antonio Nariño, Colombia. Arquitecta del Politecnico di Milano (Italia), Magister en Planificación Urbana y Territorial para

Países en Vía de Desarrollo (Istituto Universitario di Architettura

di Venezia, IUAV, Italia). Doctora en Geografía la Universidad de

Barcelona. Miembro del grupo de investigación: Ciudad, Medio Ambiente y Hábitat popular, Facultad de Artes, Universidad Antonio Nariño. Líder de la Red de lo Patrimoniable.

E-mail: lili.fracasso@uan.edu.co ORCID: http://orcid.org/0000-0003-4344-259X
\end{abstract}

\footnotetext{
**Arquitecta de la Universidad Nacional de Colombia, Especialista en Finanzas Corporativas de la Escuela de Ingeniería de Antioquia. Doctora en Historia, Arquitectura y Diseño de la Universidad Internacional de Cataluña. Miembro del grupo de investigación: ciudad, medio ambiente y hábitat popular, Facultad de Artes, Universidad Antonio Nariño. E-mail: samega2016@uan.edu.co ORCID: https://orcid.org/0000-0002-4920-515X
}

\section{Palabras clave:}

Hábitat popular, patrimonio cultural, patrimoniable, axiología.

\section{Key words:}

Popular habitat, cultural heritage, heritageable, axiology.

Recibido: 31/08/2018 
En el debate internacional rigen tres direcciones principales que orientan los criterios de valoración y valorización del patrimonio cultural mundial: la estética y la propagación de categorías de bienes patrimoniales; el significado identitario para la recuperación de una concepción unitaria del patrimonio cultural, a menudo improbable; y finalmente, el valor mercantil del patrimonio cultural, aprovechado principalmente en los circuitos turísticos. Este artículo de reflexión argumenta la importancia de considerar la pertinencia de una cuarta dirección del patrimonio cultural, que podría emprenderse en la política pública nacional para armonizar las otras tres y acercarlas a la realidad urbana y al mundo ordinario en Colombia. Se propone la dirección de lo patrimoniable, cuya valoración nace desde abajo hacia arriba y difiere de otras lógicas interesadas en las cantidades calculadas con base en flujos turísticos o la normativización de estándares. Lo patrimoniable emerge de las prácticas, sociales, estéticas, artísticas, y adquiere significado in situ a partir de procesos participativos y colaborativos. La propuesta se encamina hacia la construcción de un sistema axiológico complejo, que parte de indicadores cualitativos y datos empíricos considerados como valor de contexto y enunciados de subjetivación social y política.

\section{Abstract:}

In the current debate about cultural heritage, there are three main recognized directions through which public policy guides the criteria of valorization: the primacy of aesthetics and the multiplication of categories of goods; the identity meaning and the recovery of a unitary conception of cultural heritage; and finally, the commercial value of cultural heritage. This article presents a reflection, derived from a multiannual research process, arguing the importance of a fourth direction of cultural heritage that public policy should undertake and harmonize with the other three, that of the "heritageable", that differs from rationally and numerically calculated quantities based on tourist flows or normative standardization. The "heritageable", explored by collaborative artistic practices, acquires meaning mainly in-situ through participatory and co-elaborative processes. The research guided towards the construction of a complex axiological system, based on qualitative indicators and empirical data emerging through artistic practices, produce information essentially as statements of social and political subjectivities. 
En el actual debate acerca del patrimonio cultural se reconocen tres direcciones principales que, en la política pública, orientan los criterios de valorización. Estas corresponden a concepciones que coexisten en la realidad y que, sin embargo, podrían chocar entre sí, entrar en contradicción, e incluso degenerarse cada una, causando la depauperación del mismo patrimonio cultural (Baldacci, 2015). En primer lugar, reconocemos el primado de la estética y la multiplicación de categorías de bienes, arqueológicos, etnográficos, arquitectónicos, históricos, archivísticos, entre otros. En segundo lugar, el significado identitario y la recuperación de una concepción unitaria del patrimonio cultural, que permite superar la visión fragmentada de los bienes. Finalmente, el valor mercantil del patrimonio cultural, con sus posibles matices, que encuentra en los circuitos turísticos, museográficos y expositivos posibilidades tanto de creación de estructuras como de ocasiones culturales y de gestión para la conservación, tanto como para las actividades comerciales (Baldacci, 2015).

Más allá del bien patrimonial considerado individualmente, el artículo propone una cuarta dirección de debate y valoración que se basa en la concepción de patrimonio cultural, adoptando la acepción de lo patrimoniable, tal como surgió del proyecto de investigación ${ }^{2}$ que explora de forma participativa el patrimonio local en el hábitat popular. A continuación, se argumenta que existe otro patrimonio cultural, que está presente no solo en zonas antiguas y tradicionales asociadas la mayoría de las veces con las grandes capitales del viejo continente. Por el contrario, existen variaciones al tema arte-patrimonio-cultura que rescatan otros contextos, entre los cuales también se encuentra el hábitat popular. La cuarta dirección del patrimonio cultural que la política pública debería emprender y armonizar junto con las tres anteriormente mencionadas es la de lo patrimoniable, cuya valoración difiere de las cifras y estadísticas calculadas con base en flujos turísticos o la normativización

\footnotetext{
${ }^{2}$ Proyecto de investigación de la Universidad Antonio Nariño, Facultad de Artes, investigadora principal Arq. Liliana Fracasso Ph.D. Primera etapa de la investigación (julio 2015 hasta julio 2017) Prácticas artísticas experienciales para el reconocimiento de lo patrimoniable en Colombia: el hábitat popular y el hábitat ancestral contemporáneo en lugares piloto. Municipio de Choachí, Barrios Pardo Rubio, El Minuto de Dios, Las Cruces, Pañuelito, la localidad Rafael Uribe Uribe, Municipio de Facatativá (cod. 2015207). Segunda etapa de la investigación Hábitat popular y creación artística: elaboración de un dispositivo para el análisis de lo patrimoniable en el área de borde urbano (cod. 2017204). En las dos etapas han participado la Universidad El Bosque (CO), la Universidad Federal de Goiás-Media Lab (BR), el Museu Aberto (BR); La Casa Voladora (ES), la Accademia Albertina di Belle Arti di Torino (IT), el Museo de Arte Contemporáneo de Bogotá (CO), GIPRI (CO), los colegios San Martín de Porres y El Hato, colectivos y asociaciones que se han ido sumando al proceso de investigación-creación colaborativo (Smoking Family, Nazari Sound, Latin Fury, Abya Yala, Cohitepa, entre otros). En la etapa en curso, participan las facultades de Ingeniería Ambiental y Psicología de la UAN, la Universidad El Bosque, la Universidad Nacional de Colombia y la Universidad Federal de Goiás con el Media Lab.
} 
de estándares. Lo patrimoniable se basa en un sistema axiológico complejo, que adquiere significado principalmente in situ por medio de procesos participativos y colaborativos que se expresan a partir de indicadores cualitativos, concebidos esencialmente como enunciados de subjetivación social y política.

El texto se divide en cuatro partes: la primera presenta el significado de patrimonio cultural y su relación crítica con la postmetrópoli, en el marco institucional internacional y nacional. En el segundo apartado se explica el concepto de lo patrimoniable y su relación con el mundo ordinario. La tercera parte se encarga de la aproximación teórico-metodológica del estudio de lo patrimoniable. En el cuarto apartado se habla de su valor de contexto. Por último, se argumentan posibles perspectivas para su valoración, que mantienen como referente pragmático el caso de los lavaderos comunitarios del Barrio El Paraíso, los cuales hacen parte de los lugares observatorio de la Red de lo patrimoniable ${ }^{3}$. Finalmente, se concluye que la valoración de lo patrimoniable, a diferencia de la del patrimonio cultural, necesita de una lógica difusa que es la que mejor se ajusta a la realidad de cada contexto.

\section{Patrimonio cultural en Colombia}

Un importante eje de la política de la Organización de las Naciones Unidas para la Educación, la Ciencia y la Cultura (UNESCO) concierne la protección del patrimonio y el fomento de la creatividad. A nivel internacional, se reconoce que la cultura tiene el poder de transformar las sociedades, en la medida en que sus diversas manifestaciones (monumentos históricos y museos, ritos tradicionales y el arte contemporáneo) enriquecen nuestro día a día de múltiples maneras. En ese sentido, el patrimonio constituye una seña de identidad y favorece la cohesión de las comunidades, mientras que la creatividad contribuye a la edificación de sociedades abiertas, inclusivas y pluralistas. El patrimonio y la creatividad contribuyen así a la construcción de sociedades del conocimiento dinámicas, innovadoras y prósperas (UNESCO, s.f.).

La UNESCO, por medio de convenios culturales subscritos por varios países, ha venido conformando una plataforma mundial única para la cooperación internacional, y ha establecido un órgano de gobierno cultural completo, basado en los derechos humanos y los valores comunes. Conforman dicha plataforma, en orden cronológico: la Convención de la Haya para la Protección de Bienes Culturales en

${ }^{3}$ Marca registrada Resolución N.ํ 10927. República de Colombia, Superintendencia de Industria y Comercio. caso de Conflicto Armado (1954); la Convención sobre la Protección de los Derechos de Autor y Derechos Conexos (1952, 1971); Convención sobre las medidas que deben adoptarse para prohibir e impedir la importación, exportación y la transferencia de propiedad ilícitas de bienes culturales (1970); Convención para la Protección del 
Patrimonio Mundial Cultural y Natural (1972); Convención de la UNESCO sobre la Protección del Patrimonio Cultural Subacuático (2001); Declaración Universal sobre la Diversidad Cultural (2001); la Convención para la Salvaguardia del Patrimonio Cultural Inmaterial (2003), y, finalmente, la Convención sobre la Protección y la Promoción de la Diversidad de las Expresiones Culturales (2005).

Cada convención amplía, a nivel universal, el concepto de patrimonio que se reconoce como tangible, intangible, material e inmaterial. Esta situación ha generado al mismo tiempo importantes desafíos en materia de gestión en el ámbito nacional y local. Mucho se quiere proteger; sin embargo mucho más se ve amenazado por la urbanización sin control, las demoliciones y las renovaciones urbanas efectuadas como estrategia de respuesta a la especulación edilicia y las crisis económicas (Capel, 2014).

En Colombia, el artículo 8 de la Constitución Política reconoce que "es obligación del Estado y de las personas proteger las riquezas culturales y naturales de la Nación"; esto se complementa con los artículos 63, 72, 82, 95, 101, 102, 313, 332 y 333. Con la Ley 397 de 1997 (Ley General de Cultura, art. 4) se define patrimonio cultural de la Nación como:

El patrimonio cultural de la Nación está constituido por todos los bienes y valores culturales que son expresión de la nacionalidad colombiana, tales como la tradición, las costumbres y los hábitos, así como el conjunto de bienes inmateriales y materiales, muebles e inmuebles, que poseen un especial interés histórico, artístico, estético, plástico, arquitectónico, urbano, arqueológico, ambiental, ecológico, lingüístico, sonoro, musical, audiovisual, fílmico, científico, testimonial, documental, literario, bibliográfico, museológico, antropológico y las manifestaciones, los productos y las representaciones de la cultura popular. 
La Ley 1185 de 2008 sobre Bienes de Interés Cultural (BIC) y la Lista Representativa de Patrimonio Cultural Inmaterial de la Nación (LRPCI) actualizan dicha definición de patrimonio cultural y definen los procedimientos para declarar los BIC o incluir nuevas manifestaciones en la LRPCI. El Decreto 763 de 2009 define el patrimonio material, y lo divide en bienes muebles y bienes inmuebles; además el artículo 6 establece los criterios de valoración (antigüedad, autoría, autenticidad, constitución del bien, forma, estado de conservación, contexto ambiental, contexto urbano, contexto físico, representatividad y contextualización sociocultural) e incluye los valores histórico, estético y simbólico.

El patrimonio inmaterial se define en el Decreto 2941 de 2009, e incluye en el artículo 8, Campos de alcance de la Lista Representativa de Patrimonio Cultural Inmaterial, las siguientes manifestaciones: lenguas y tradición oral; organización social; conocimiento tradicional sobre la naturaleza y el universo; medicina tradicional; producción tradicional; técnicas y tradiciones asociadas a la fabricación de objetos artesanales; artes populares; actos festivos y lúdicos; eventos religiosos tradicionales de carácter colectivo; conocimientos y técnicas tradicionales asociadas al hábitat; cultura culinaria; patrimonio cultural inmaterial asociado a los espacios culturales. El artículo 9 define los criterios de valoración para incluir manifestaciones culturales en la LRPCI: pertinencia, representatividad, relevancia, naturaleza e identidad colectiva, vigencia, equidad y responsabilidad.

Los procedimientos de ingreso a la LRPCI se determinan por medio de la Resolución 330 de 2010, por la cual se desarrollan algunos aspectos técnicos relativos al Patrimonio Cultural de la Nación de naturaleza inmaterial.

Por lo general, en Colombia, las manifestaciones que se han venido incluyendo en dicha lista corresponden a actos festivos y lúdicos, artes populares y eventos religiosos, sumados a categorías más amplias como lengua y tradición oral, organización social o patrimonio cultural inmaterial asociado a espacios culturales (es decir, a modos de vida tradicionales).

La inclusión de las manifestaciones culturales en listas representativas para la 


\begin{tabular}{|l|l|}
\hline 2017 & Cantos de trabajo de los Llanos de Colombia y Venezuela \\
\hline \multirow{2}{*}{2015} & $\begin{array}{l}\text { Música de marimba y cantos y bailes tradicionales de la región colombiana del } \\
\text { Pacífico Sur y de la provincia ecuatoriana de Esmeraldas } \\
\text { El vallenato, música tradicional de la región de la Magdalena Grande }\end{array}$ \\
\hline 2012 & Fiesta de San Francisco de Asís en Quibdó \\
\hline 2011 & Los conocimientos tradicionales de los chamanes jaguares de Yuruparí \\
\hline 2010 & El sistema normativo de los wayuus, aplicado por el pütchipü'üi ("palabrero") \\
\hline \multirow{2}{*}{2009} & El Carnaval de Negros y Blancos \\
\cline { 2 - 2 } & Las procesiones de Semana Santa de Popayán \\
\hline \multirow{2}{*}{2008} & El Carnaval de Barranquilla \\
\cline { 2 - 3 } & El espacio cultural de Palenque de San Basilio \\
\hline
\end{tabular}

\begin{tabular}{|c|l|}
\hline 2014 & Qhapac Ñan - Sistema vial andino \\
\hline 2011 & El paisaje cultural del café de Colombia \\
\hline 2006 & Santuario de fauna y flora de Malpelo \\
\hline 1995 & $\begin{array}{l}\text { Centro histórico de Santa Cruz de Mompox } \\
\text { Parque Arqueológico de San Agustín } \\
\text { Parque Arqueológico Nacional de Tierradentro }\end{array}$ \\
\hline 1994 & Parque Nacional de los Katios \\
\hline 1984 & Puerto, fortalezas y conjunto monumental de Cartagena \\
\hline
\end{tabular}

Tabla 2. Patrimonios de la humanidad en Colombia.

Fuente: UNESCO (https://whc.unesco.org/es/list/).

UNESCO ha suscitado debates y críticas, pues se han venido generando unas listas de patrimonio inmaterial análogas, pero antagónicas, a las de patrimonio material, en una visión dicotómica (Andrade Pérez, 2013). La selección de las manifestaciones culturales de un país tan complejo y diverso como Colombia podría tender a establecer una forma de representatividad incompleta, que dejaría por fuera muchas otras expresiones culturales. Además, dicha idea de patrimonio cultural inmaterial tiende a "cosificar" a las manifestaciones y a desarticularlas de la vida cotidiana de las personas (p. 55).

Nos preguntamos: ¿Qué pasa con todo lo que no está incluido y que no se incluirá 


\begin{tabular}{|c|c|c|}
\hline Bolívar & Chocó & Valle del Cauca \\
\hline $\begin{array}{l}\text { Zona litoral norte: } \\
\text { Baile del Negro } \\
\text { Mapalé } \\
\text { Zonas de montes y sabanas: } \\
\text { Tambora } \\
\text { Chandé } \\
\text { Otras expresiones del folclor } \\
\text { bolivarense: } \\
\text { Cumbia } \\
\text { Bullerengue }\end{array}$ & $\begin{array}{l}\text { Bailes tradicionales chocoanos: } \\
\text { Contradanza } \\
\text { Jota } \\
\text { Abozao } \\
\text { Andarele o anderete } \\
\text { Aguabajo } \\
\text { Caderota } \\
\text { Moña o fox-trot } \\
\text { Son chocoano } \\
\text { Pasillo chocoano en el municipio de Atrato; además del abozao en todo el } \\
\text { Chocó, la polca, contradanza, la moña en Novita; tamborito en la Costa } \\
\text { Pacífica; saporrondón en la Costa y el Atrato; estro en el Baudó; mazurca } \\
\text { en el Atrato; biborona en Pizarro; danza en Atrato y San Juan, aguabajo } \\
\text { en Atrato, San Juan y Baudó; quilele en Condoto, bambasú en Istmina; } \\
\text { torbellino en Atrato, San Juan y la Costa Paćífica }\end{array}$ & $\begin{array}{l}\text { Currulao } \\
\text { Bambuco }\end{array}$ \\
\hline $\begin{array}{l}\text { Archipiélago de San Andrés, } \\
\text { Providencia y Santa Catalina }\end{array}$ & Tolima & Cauca \\
\hline $\begin{array}{l}\text { Mazurca } \\
\text { Schottische } \\
\text { Polea } \\
\text { Two-step y half-an-a-half } \\
\text { Waltz } \\
\text { Slow Waltz } \\
\text { Calypso } \\
\text { Mentó } \\
\text { Quadrille } \\
\text { Pasillo }\end{array}$ & $\begin{array}{l}\text { Pasillo } \\
\text { Torbellino } \\
\text { Guabina } \\
\text { Sanjuanero }\end{array}$ & $\begin{array}{l}\text { Bambuco Sotareño } \\
\text { Rioblanqueño } \\
\text { Fuga } \\
\text { Currulao } \\
\text { Bambuco patiano }\end{array}$ \\
\hline
\end{tabular}

Tabla 3. Danzas colombianas de mestizaje u origen afro incluidas en el Sistema Nacional de Información Cultural (SINIC). 
en dichas listas? ¿Qué pasa realmente con los lugares simbólicos tradicionales y con la comunidad después de la inclusión del patrimonio en las listas? En un mundo tan cambiante, el dinamismo del espacio urbano genera rápidas transformaciones y enormes plusvalías que dificultan la atribución de significado a los lugares y a la protección del patrimonio cultural. Por ello, la excepcionalidad que se busca atribuir a algunos bienes patrimoniales recuerda un poco al enunciado de que "los árboles no dejan ver el bosque", o también al proverbio confuciano: "cuando el sabio señala a la luna, el necio mira al dedo".

Los procesos mundiales de la globalización, la informatización y la expansión urbana han transformado profundamente la ciudad contemporánea. Se han generado así profundas rupturas de los cánones de la ciudad moderna, situación que demanda nuevas herramientas y nuevas categorías de análisis para interpretar la metrópoli postmoderna (postmetrópoli). Hoy en día, la ciudad está en todas partes y en todo. Está sometida a preguntas contradictorias, la deseamos como "madre" y como "máquina" o instrumento al mismo tiempo (Cacciari, 2010). La forma urbis tradicional de la ciudad se ha disuelto, la ciudad es solamente una unión de lugares de producción y de mercado: cada sentido de la relación humana se reduce a la producción, el intercambio y el comercio. La ciudad ya no es ni polis ni civitas, sino, al decir de Platón, una sinoiquia, es decir, una cohabitación. Los lugares simbólicos tradicionales desaparecen, quedan sofocados por los lugares de intercambio que son expresión de la movilidad de la ciudad. Es la argumentación de Massimo Cacciari, filósofo, y alcalde de Venecia, quien añade: "hemos hospitalizado nuestra memoria, así como nuestras ciudades históricas, haciendo de ellas museos” (Cacciari, 2010 p.32 ).

Desaparecen, en la posmetrópolis, las dimensiones de los lugares simbólicamente significativos. Cacciari advierte que no es posible habitar una ciudad, si esta no se dispone para habitar, si no proporciona "lugares".

El lugar es allí donde nos paramos: es pausa; es algo análogo al silencio de una partitura. La música no se produce sin el silencio. El territorio postmetropolitano ignora el silencio, no nos permite pararnos, "recogernos" en el habitar. La posmetrópolis no conoce, no puede conocer distancias: éstas son sus enemigos pero no podemos eliminar espacio mientras sigamos siendo cuerpo. (pp. 35-36) ¿Qué habitamos hoy? ¿Habitamos ciudades? No, habitamos territorios. (p. 52) Vivimos en un territorio desterritorializado. Habitamos unos territorios cuya métrica ya no es espacial [sino temporal]. La pérdida de "valor simbólico" de la ciudad crece [...] asistimos a un desarrollo sin objetivos [...] insensato... un proceso que no representa ninguna dimensión orgánica. (pp. 54-55) (Cacciari, 2010). 
En la dinámica descrita en el párrafo anterior, propia de la ciudad postmoderna, el hábitat popular es espacio codiciado, especialmente el que está presente en los sectores urbanos más céntricos o en proximidad de los sistemas ecológicos; o en aquellos espacios que, casi al azar, porqué es difícil predecir lo que el mercado considera "vacío" para ser llenado, son afectados por megaproyectos que buscan generar "acontecimientos", como propone Massimo Cacciari: "Se trata de un espacio para acontecimientos, organizado según medidas temporales, y el territorio se presenta como una colación de acontecimientos" (Cacciari, 2010, p. 58). El hábitat popular se ve amenazado por procesos de urbanización, elitización y gentrificación, así como por procesos de estetización que transforman lo cotidiano en espectáculo para visitantes o turistas. El hábitat popular queda de este modo constantemente desprotegido.

El concepto de hábitat, así como el de paisaje, resulta entonces integrador, expresión de diferencias y de resistencia cultural. Frente a los procesos de desterritorializaciónreterritorialización necesitamos reconocer el hábitat popular y el "hábitat ancestral contemporáneo" (tal como lo definen las comunidades indígenas que han dejado a la fuerza sus territorios de origen y viven en Bogotá) $)^{4}$ como patrimonio cultural. Los procesos de transformación de dichos hábitats se están dando de forma demasiado rápida, orientados por la ley de mercado y la globalización económica. La reterritorialización es generada por el mercado y no por la sociedad. Además, en un país como Colombia, dichos procesos se hacen más dramáticos a causa de la violencia atávica.

Tal como lo resume Jaime Hernández:

\footnotetext{
${ }^{4}$ El término "hábitat ancestral contemporáneo" surge en el marco de la investigación, a través del trabajo con una comunidad INGA de Bogotá, en uno de los Observatorios de lo patrimoniable, en la localidad Rafael Uribe Uribe.
}
... los sectores del hábitat popular son aquellos sectores de ciudad con características económicas y sociales particulares que se van desarrollando y consolidando con el tiempo, donde conviven, muchas veces mezcla- dos, varios orígenes y formas de producir y expresar ciudad. Pero, cuyo común denominador son los pobladores, pobladores que a medida de sus posibilidades y de los espacios económicos, sociales y de participación, van creando, transformando, mejorando y dándole forma y expresión a su habitar (2005, p.49).


Existen instancias internacionales que aportan a la categoría de hábitat popular como patrimonio cultural. ${ }^{5}$ También hay iniciativas incipientes, como la de la organización social TECHO Internacional, que trabaja con habitantes de más de 600 asentamientos populares en 19 países de América Latina, para solicitar a la UNESCO el reconocimiento como Patrimonio de la Humanidad de la realidad urbana en que viven millones de personas en América Latina, denominada como villa miseria.

Les solicitamos que declaren a nuestros asentamientos como Patrimonio de la Humanidad, para conseguir que los ojos del mundo reconozcan la realidad que más de 104 millones de personas vivimos a diario, y se acerquen a trabajar con nosotros para superar esa desigualdad. (Mary Silveira en El Clarín, 2018).

Recientemente se discute el reconocimiento por parte de la UNESCO de las periferias de las ciudades como patrimonio cultural urbano (UNESCO, 2016). En Colombia, no obstante, todavía no hay evidencias de reconocimiento del valor del hábitat popular como patrimonio.

\footnotetext{
${ }^{5}$ Convención Europea del Paisaje, en Florencia (Italia, 20.10.2000), en su definición de patrimonio paisajístico: “Cualquier parte del territorio tal y como la percibe la población, cuyo carácter sea el resultado de la acción y la interacción de factores naturales y/o humanos" (art. 1 - Definiciones. Convenio europeo del paisaje).

UNESCO: Proclamación de las Obras Maestras del Patrimonio Oral e Inmaterial de la Humanidad (2001-2005), en la definición misma de patrimonio inmaterial (Convención para la salvaguardia del patrimonio cultural inmaterial, París, 17 de octubre de 2003, art. 2 - Definiciones).

ICOMOS: Definición de patrimonio vernáculo (Introducción, Carta del Patrimonio Vernáculo Construido, 1999; ratificada por la 12a Asamblea General en México, en octubre de 1999); Carta internacional sobre turismo cultural. La Gestión del Turismo en los sitios con Patrimonio Significativo (1999).

Convenio Andrés Bello (CAB): Encuentro Somos Patrimonio, 1997; Premio CAB Somos Patrimonio (2014), y la concepción de patrimonio de apropiación social.

Finalmente, la producción social del hábitat y la vivienda, en la Carta Mundial por el Derecho a la Ciudad (2004, art. IV).
} 
De la valoración sacralizada del monumento histórico excepcional hemos pasado al reconocimiento, recuperación y disfrute de algo tan cotidiano como, por ejemplo, el refrán popular.

Pierre Nora, 1986

El concepto de lo patrimoniable en nuestro propósito investigativo busca subvertir los discursos hegemónicos que no reconocen el hábitat popular como patrimonio cultural, porque privilegian una visión universal, totalizante y totalitaria del valor patrimonial. Lo patrimoniable concierne por su parte al mundo ordinario.

\begin{abstract}
Preguntas de contexto que apuntan al origen del sistema dentro del cual, por ejemplo, hacer una silla, sentarse, golpear una puntilla con un martillo, reunir ladrillos para hacer una casa y pedir agua en un vaso tienen sentido. Este tipo de preguntas, que interrogan el ser de las cosas, es el que abre el arte. La entrada del arte interrumpe el sentido de la cotidianidad e inaugura preguntas de contexto [...]. Al interrogar la habitualidad de lo ordinario, se hacen visibles estructuras organizativas que constituyen el sentido de ese orden. Solo después de su puesta en problema es posible captar temáticamente los presupuestos de sentido - nunca enunciados explícitamente- de un contexto. (Toledo Castellano, 2017, p. 9).
\end{abstract}

En términos generales, podemos definir la categoría de lo patrimoniable como un acuerdo colectivo, que se establece de forma dialéctica en comunidades heterogéneas y en contextos geográficos diversos. Asimismo, representa las subjetividades y las subjetivaciones, la relación con el lugar y sus temporalidades. Está dirigido a valorar los procesos de territorialización que se han formado de manera paulatina con creatividad y relativamente pocos recursos. Se basa en el re-conocimiento dialógico y mutante del bien común, y la vinculación emocional del sujeto, individual y colectivo, con él mismo.

Lo patrimoniable es un concepto clara e intencionalmente borroso, con todas las potencialidades que esto conlleva, en términos de la capacidad de ajustarse a la realidad de cada contexto. Ludwig Wittgenstein escribió (2008, primer edición 1953 ):

¿Pero es un concepto borroso en absoluto un concepto? ¿Es una fotografía difusa en absoluto una figura de una persona? sí; ¿Puede siempre reemplazarse con ventaja una figura difusa por una nítida? ¿No es a menudo la difusa lo que justamente necesitamos? (p.91). 
Lo que necesitamos para la defensa y protección del patrimonio cultural se basa en la apropiación social del mismo, y refiere precisamente al uso de un concepto borroso como lo patrimoniable. La incertidumbre asociada a la valoración de este concepto resulta tan estimulante y prácticamente útil como el tratamiento de la incertidumbre en la matemática. En dicho campo de conocimiento, apropiarse y procesar expresiones lingüísticas que definen de forma muy descriptiva reglas o valores (lejos, muy cerca, bastante, etc.) ha requerido quebrantar la lógica convencional y alcanzar una lógica difusa, concepto creado hacia la década de 1960 por Lofti A. Zadeh, catedrático de la Universidad de Berkeley (California).

\section{La lógica difusa es una lógica multivaluada que permite representar mate- máticamente la incertidumbre y la vaguedad, proporcionando herramientas formales para su tratamiento. \\ Como indica Zadeh, "Cuando aumenta la complejidad, los enunciados precisos pierden su significado y los enunciados útiles pierden precisión”, lo cual puede resumirse [en el enunciado ya mencionado]: "los árboles no te dejan ver el bosque". (González Morcillo, s.f., p. 7).}

Existen términos lingüísticos que describen el valor del patrimonio cultural para una comunidad, que resultan explícitos y evidentes para la misma y que, sin embargo, podrían no significar nada o significar poco en la lógica convencional que permite el reconocimiento, la catalogación y la inclusión en una lista (BIC o LRPCI). Dicha lógica convencional, al igual que en matemática, no es entonces adecuada para procesar este tipo de reglas.

La definición del patrimonio cultural es un proceso que manifiesta relaciones estrechas entre el territorio y la identidad, las relaciones de poder y las aspiraciones culturales (Bogumila Lisocka-Jaegermann, 2004, p.9). En la idea de Cantón Arjona los bienes patrimoniales plantean siempre problemas de interpretación (Cantón Arjona, 2013). En este sentido, cabe destacar con las palabras del filósofo Samuel Arriarán que: "La interpretación es siempre un acercamiento de lo subjetivo. La interpretación viene de adentro", y con esta mirada que se dirige hacia dentro, hacia el punto ciego, buscamos lo patrimoniable en contextos territoriales concretos, conscientes de que, tal como lo recuerda David Harvey: "Algunos hombres saben conmutar el patrimonio cultural en espacios de esperanza y otros, más avispados y egoístas, en renta de monopolio" (Harvey, 2013, p. 163). El mismo Arriarán nos recuerda que:

La memoria no está en el pasado, está en el futuro. Conectar el pasado con el presente y con el futuro es lo que se pierde cada vez más. Todo es cuestión de interpretación, todo es ficción, no hay hechos objetivos. Esta capacidad imaginativa hace que estemos siempre más allá de la ideología, y nuevas utopías, porque la historia no se acaba. 


\title{
Aproximación y metodología
}

Con un enfoque territorial, exploramos el valor del hábitat popular con base en unas prácticas artísticas colaborativas, presentes o propuestas, en unos lugaresobservatorio de Bogotá y sus alrededores ${ }^{6}$. Indagamos el valor que los habitantes (y no necesariamente las instituciones estatales), atribuyen, por varias razones, a bienes materiales, manifestaciones culturales inmateriales o bienes naturales del propio contexto.

\begin{abstract}
Debemos confrontarnos no con una naturaleza abstracta, sino con aquello que podemos considerar un neoecosistema producto del hombre, derivado de las relaciones dinámicas entre ambiente natural, ambiente construido y ambiente entrópico. De estas relaciones emergen los territorios, los lugares, que son sujetos culturales, hablan, dialogan sobre el largo proceso de antropización a través del paisaje; restituyen identidad, memoria, lengua, culturas, materiales, mensajes simbólicos y efectivos (Magnaghi, 1998, p. 34, traducción libre).
\end{abstract}

En los lugares-observatorio de lo patrimoniable, las prácticas artísticas representan una unidad de análisis, y al mismo tiempo un proceso de creación, que lleva a la construcción de una "cartografía tópica" (Turco, 2010) de los lugares donde se realizan dichas prácticas. De forma parecida a la investigación cualitativa, los elementos que caracterizan a la investigación basada en las artes, promueven, entre otros aspectos: la polifonía; la individualización de los informadores; el mantenimiento de un carácter dialógico también con quienes leen los textos resultados de la investigación, ya que los lectores se ven implicados en las historias de vida de personas específicas, con nombre propio y apellido.

La conceptualización de lo patrimoniable es un proceso de investigación que

${ }^{6}$ Municipio de Choachí, municipio de Facatativá, Bogotá D.C. (barrios Pardo Rubio, El Paraiso, El Minuto de Dios, Las Cruces, El Pañuelito, localidad Rafael Uribe Uribe en el que está presente la comunidad Inga inmigrada a Bogotá y que procede del Valle del Sibundoy). involucra la comunidad y sus lugares, los investigadores y socios activos en otros países, favoreciendo una aproximación inductiva cuando trabaja con datos cuantitativos y cualitativos, procedentes de las prácticas artísticas, y asimismo una aproximación de tipo deductivo, en el sentido que se aclara a continuación.

El valor de las prácticas artísticas, según Bauman (2009) es precisamente dar voz a lo inefable, volver tangible lo invisible, demostrar indirectamente que no existe una sola forma o una sola voz para participar y contribuir en el proceso interminable de creación de sentido de la realidad; representa asimismo el esfuerzo heroico del artista contemporáneo. 
Las prácticas artísticas en los lugares del proyecto son partes integrantes de un primer mapeo de los valores de contexto, siendo al mismo tiempo una unidad de análisis y de creación (investigación-creación). La investigación basada en las artes es otra manera de entender el conocimiento utilizando métodos y procesos creativos y artísticos para acercarse al mismo. Es otra forma de hacer investigación en la que, a diferencia del método científico, no se sabe de antemano el experimento que se va a realizar, y resulta una forma primaria de entender y examinar la experiencia, tanto de los investigadores como de las personas involucradas en sus estudios (McNiff, 1998), con un significado que emerge a través del proceso de la expresión creativa para responder a preguntas en donde la teoría y la práctica se entremezclan. En este tipo de investigación, es la estética la que conduce al significado, y la estética va más allá de querer demostrar hechos. La aproximación pretende otra manera de mirar y representar la experiencia; realzar perspectivas, sin buscar certezas; señalizar matices y lugares no explorados. Trata de representar y acceder a voces o perspectivas marginalizadas, de develar aquello de lo que no se habla, de lo que no se ve, o no está escrito para visibilizarlo. Para ello, utiliza elementos artísticos y estéticos, datos empíricos que pasan por diferentes tipos de análisis. El ser, la subjetividad y la autobiografía son las principales herramientas metodológicas; adicionalmente la práctica reflexiva, la auto-etnografía, los estudios de performance y la investigación documental. El método toma como recurso la narrativa propia del sujeto, es decir, asume la autobiografía como una manera de explicar fenómenos sociales, artísticos y culturales más amplios.

${ }^{7}$ En la categoría patrimoniable es posible reconocer el quid pro quo ya aparecido en el concepto de utopía de Ernst Bloch, resumido en las palabras en alemán noch nicht, que pueden traducirse en español de dos maneras: "todavía no" (carencia) y "aún no" (esperanza) (Levitas, 2008).
La aproximación deductiva a la investigación tiene referencia con las dimensiones ideológica y material, y los aspectos subjetivos y objetivos de lo patrimoniable que se aproximan a la idea de utopía concreta de Ernst Bloch y del todavía-no7(Levitas, 2008). Las categorías blochianas que definen la utopía concreta se basan en deseos utópicos: conciencia anticipadora, imagen desiderativa e identidad; por hipótesis, entran a caracterizar los discursos y las prácticas artísticas en los lugares-observatorio. La función de la utopía concreta queda, por su parte, definida por otras categorías: protesta; optimismo militante; esperanza; imágenes y cultura (función de futuro); mundos alternativos (el más acá). Por consiguiente, el valor de las prácticas artísticas para el reconocimiento de lo patrimoniable en el hábitat popular se interpreta análogamente a la función de la utopía concreta en los lugares-observatorio. 
El todavía-no de lo patrimoniable se refiere a que no está indicando que llegará a ser "patrimonio cultural", en el sentido de su inclusión en la Lista de bienes declarados BIC del ámbito nacional o la LRPCI de la Humanidad. No es necesariamente la "lista" el mecanismo de gestión de lo patrimoniable, en tanto se espera que la identificación, reconocimiento y visibilización de lo patrimoniable ofrezca mecanismos o lineamientos de política para garantizar derechos. Fundamentar lo patrimoniable en el pensamiento blochiano significa, por una parte, destacar la función que ocupa la utopía concreta como punto de arranque, lo que nos permite criticar el ser presente (Gálvez Mora, 2008). Por otra, significa anticipación imaginaria: junto a la imagen de la identidad que se pretende, muestra los problemas de su realización (Martínez Contreras, 2004, p. 27). La identidad en Bloch se configura a lo largo de toda una vida, en sus palabras: "Yo soy, pero no me tengo. Por eso, antes que nada, devenimos" (Bloch, cit. en Martínez Contreras, 2004, p. 19). La dimensión utópica de lo patrimoniable tiene como posible función la gestación de embriones de organización comunitaria para formas postcapitalistas de habitar (Capel, 2014), que en determinados contextos ya existen a micro escala y que esperan hacerse visible, como lo patrimoniable, en otros contextos y a otra escala, desde un pensamiento trans-escalar.

\section{Valor de contexto}

Al concebir el patrimonio cultural como valor de contexto, al igual que sucede con el paisaje, se asume como relevante su significado integrador, merecedor de protección jurídica específica, y la acción dramatúrgica del sujeto de inscripción de su historia en el espacio. Nos referimos a la identidad narrativa, que constituye la manera como el sujeto se auto-representa (sobre la base de predicados: yo soy así, hago esto o aquello), como el protagonista de una historia que él vive en la ciudad. La identidad narrativa no pertenece a un individuo encerrado en sí mismo, sino que es por definición la de un sujeto participativo: "Quienes viven la ciudad inscriben su propia dramaturgia en aquella ciudad, construyen en la ciudad y con la ciudad su perfil de protagonista" (Turco, 2010). Las prácticas artísticas comunitarias, como dispositivos narrativos que transforman el territorio y el contexto territorial en paisaje (landscaping), se constituyen como las únicas aptas para investigar y valorar lo patrimoniable, y para activar el dispositivo narrativo que permite reconocerlo en el hábitat popular. Lo anterior hace parte tanto de una identidad territorial como de una identidad narrativa. Así, la valoración axiológica de lo patrimoniable representa un campo que apenas se vislumbra, y que pasa precisamente por el reconocimiento y valoración de la identidad narrativa. 
El patrimonio cultural concebido de este modo, a partir del contexto específico, implica dar respuesta a una interesante cuestión relacionada con la polisemia cultural. La relación del patrimonio cultural con el hábitat popular se comprende considerando este último como una manifestación particular que genera actitudes, normas y valores propios. Permite además asumir la simbolización del lugar y considerar este último como un locus cognitivo especial (Gómez, 2012), ámbito donde se adensa la comunicación y donde se superponen los significados (Leone, 2008). El contexto no representa un valor en sí mismo, sino que encarna una referencia dinámica, para un determinado sistema de creencias, expectativas o esperanzas y conocimientos. Cuando el contexto se identifica como hábitat popular aplica la misma enunciación: “No es una cosa, un objeto, sino un fenómeno procesual y fluido en permanente cambio, un sistema de procesos que implican interacciones dinámicas entre el ser humano y su mundo" (Sánchez Ruiz, 2009, p.119). El sentido del contexto es cambiante, dependiendo de la sociedad que se proyecta en él, por ello se re-significa incesantemente (Leone, 2008).

Lo dicho anteriormente evidencia la dificultad para reconocer con actos formales el valor patrimonial de contexto, ya que las comunidades locales, "que son las herederas históricas del patrimonio, las que conocen su sentido, y su valor más en profundidad" (Martín Barbero, 1998), no pueden tener interlocución directa con la UNESCO, un organismo internacional que se relaciona por medio de representantes con los Estados nacionales.

Tanto a nivel central-mundial, como a nivel de estado nación, resultaría muy difícil una indagación acerca del significado que el contexto, o lugar, ha venido adquiriendo y acumulando a través de su historia en cada comunidad local. Se destaca aquí la profunda contradicción al hablar de obras de valor universal "cuando sabemos que todo valor es cultural y por lo tanto todo valor es particular (Martín Barbero, 2008), y sobre todo, "todo valor tiene siempre una referencia al lugar desde el cual se habla" (Martín Barbero, 2010). 
Indagar acerca del valor de contexto plantea cuestiones como estas: ¿Cómo se produce el valor del hábitat popular? ¿Cómo se difunde y deposita? Dicha producción de sentido le pertenece a la comunidad local, ya que se compone de la materialidad del espacio, tanto como de percepciones, evocaciones, sensibilidad estética o moral, sentimientos, emociones, afectividad, espiritualidad, ideologías y transacciones metafóricas. No existe una relación directa entre el estado material del espacio y el estado emotivo, sino que existen transacciones metafóricas, que se dan ya sea en lo material o en lo simbólico (Turco, 2010).

Según este planteamiento, la idea de patrimonio cultural no se ajusta, por lo tanto, a una visión de universalidad totalizante y totalitaria (Martín Barbero, 1998; 2008; 2010), ya que su valor es plural y ambiguo (Cantón Arjona, 2013), razón por la cual los procesos de valorización del patrimonio cultural pueden resultar discordantes y contradictorios. La concepción de valor universal de patrimonio que defiende la UNESCO resulta crítica si no permite un "universal descentrado", que posibilite diversos valores y los ponga en diálogo, traduciendo unos a otros (Martín Barbero, 2008), en la hipótesis que esta "traducibilidad" sea posible.

\section{Posibles perspectivas de valoración}

Una perspectiva axiológica de lo patrimoniable podría reconstruirse cruzando el concepto de valor desde los campos de la filosofía, los indicadores estéticos y la valoración patrimonial. Lo anterior soportado en el trabajo investigativo desarrollado desde hace ya varios años en los lugares observatorio.

Alrededor del concepto de valor se mueven disímiles concepciones y enfoques, derivados de la filiación filosófica del pensador, su cultura, experiencias vitales y concepción científica particular (Prieto, 2002). A continuación se retomarán algunos referentes desde su historia misma, considerando que el valor es estudiado desde diferentes concepciones: naturalista, fenomenológica, intuitivista, utilitaria-pragmática, emotivista y marxista (Prieto, 2002).

En la opinión del psicólogo norteamericano Maslow, los valores poseen una biología y una genética, son desarrollados por la cultura") para Rollo May, el valor es un avance hacia una forma de conducta; por otra parte, el pensador Tomas Olagree, con una comprensión subjetivista de los valores, los refiere a ideas, imágenes, nociones. 
La definición del valor parte del propio problema fundamental de la filosofía, es decir de la relación pensar-ser. Este problema comprende cuatro aspectos, según Zorshantov y Grechanii (1985).

- Psicofisiológico: Relación entre el cuerpo y el espíritu, que comprende la naturaleza de lo psíquico y de lo físico.

- Ontológico: Lugar que ocupan los fenómenos espirituales en el mundo.

- Gnoseológico o epistemológico: Relación entre el conocimiento humano y la realidad objetiva.

- Praxiológico-valorativo: Actuación integral del hombre, su conducta.

La solución praxiológico-valorativa al problema filosófico fundamental posee por una parte su lenguaje específico: el lenguaje de los juicios valorativos, las normas y prescripciones $y$, por otra, se fundamenta en que no sólo debemos aceptar la existencia de la realidad objetiva, y actuar consecuentemente en ella, sino actuar dignamente, realizando los valores humanos.

Según Doris Prieto (2002), los aspectos fundamentales del problema praxiológicovalorativo son los siguientes:

- Relación entre la práctica histórico-social y la realidad objetiva.

- Correlación entre el sistema de valores funcionales y la estructura de la sociedad.

- Interrelación entre los valores materiales y espirituales.

- Interrelación individuo-sociedad.

Es posible en este orden de ideas definir al valor como significación social positiva de los fenómenos y procesos para satisfacer las necesidades humanas y servir a la práctica (Fabelo, 1989). 
Manteniendo como referente el sistema de indicadores estéticos sugeridos por Raúl Niño (2006), se identifican a continuación unos criterios que se ajustan aquí a la categoría de lo patrimoniable. Consideramos que es viable realizar una valoración diferente a la de las cantidades racionales y numéricas y la normativización de estándares que habitualmente se aplican en la valoración del patrimonio cultural. Coherentemente con los argumentos presentados en este texto, se plantea un sistema axiológico que se expresa más en términos subjetivos que en indicadores cuantitativos.

En este sentido, es posible plantear campos temáticos para aproximarnos a la comprensión de cómo las personas valoran, con dimensiones cualitativas:

- La construcción de relaciones.

- Las adaptaciones a variaciones de la vida urbana.

- La experiencia múltiple y diversa de la vida social en la ciudad.

- Las significaciones que se construyen en la idea de mundo como experiencia cultural.

La mirada desde la estética se basa en un lugar de interrelación de saberes, fenómenos y conocimientos. Esta visión combina el azar y la intención para percibir las cosas de otra manera, desde la diferencia, pero con un propósito: vincular relaciones diversas y complejas (Niño, 2006). La dimensión espacial está centrada en las ciudades como espacios de la vida colectiva que se recrean por la interacción social, cultural, económica, política, donde tienen lugar las transformaciones de la diversidad cultural y los procesos estéticos re-configurados constantemente en imaginarios y símbolos que inciden en la manera de abordar las formas contemporáneas de vida urbana.

Se posibilita la creación de una exploración desde campos temáticos, incluyendo los mundos simbólicos y los significados sociales, relacionados en los sistemas urbanos de habitabilidad y en los procesos que revisten las prácticas culturales de la sociedad civil:

- Relaciones de redes culturales. Apropiación y uso del espacio público en eventos y acontecimientos lúdicos y de experiencias culturales (participación colectiva).

- Formas de apropiación del paisaje urbano.

- Relaciones de valoración con el arte público de la ciudad.

- Relaciones eco-estéticas con el habitar urbano.

- Producción de la imagen urbana como parte de experiencias significativas, de las múltiples culturas emergentes del mundo urbano.

- Valoración de los comportamientos ciudadanos y las transformaciones de la percepción urbana por influencia de los medios de comunicación. 
La metodología se desarrolla en torno a la creación de estructuras conceptuales llamadas "matrices holísticas relacionales", en donde se combinan variables de cada uno de los campos temáticos. La exploración de campos temáticos a través de matrices y relaciones que se ilustran a través de gráficas en redes holísticas permite encontrar conexiones diversas entre temas, tiempos, acciones y actores, y posibles interconexiones entre problemas, soluciones, mundos simbólicos y estrategias de vida en medio de redes complejas.

\section{Conceptos dentro de los campos temáticos:}

- Exploran subjetividades: deseos, modas, formas de consumo, identidades, apropiaciones simbólicas por el territorio.

- Apropiación y uso de las tecnologías de la información y comunicación en la generación de imágenes culturales.

- Experiencias compartidas de significados que proporcionan ideas y visiones del mundo contemporáneo.

- Construcción de conocimientos, transmisión de saberes, reconocimiento de símbolos colectivos.

De esta manera, la construcción conceptual de valoración de lo patrimoniable implica procesos complejos de subjetividades individuales, a través de experiencias estéticas en términos del habitar urbano. Se configuran campos temáticos compuestos por descriptores como marco de reflexión.

A nivel teórico, la aplicación de los indicadores estéticos, tal como la concibe Niño, resulta viable solo parcialmente, ya que la valoración de lo patrimoniable fue llevada en primera instancia en el marco de la experiencia individualizada, y no colectiva, sucesivamente mediada en pequeños grupos de referencia, donde se consideró la experiencia estética en relación con la cultura urbana y su marco de acción en el ámbito de los sistemas sociales. 
Cabe preguntarse, como punto de partida para la valoración de lo patrimoniable:

- ¿Cómo se definen los valores desde la individualidad y subjetividad? (Niño, 2006, p. 15).

- ¿Cómo se re-definen dichos valores en las relaciones interpersonales?

- ¿Los símbolos de la calidad de vida y bienestar, de dónde proceden?

- ¿Qué significa la experiencia estética en medio de la heterogeneidad y diversidad social? (Niño, 2006, p. 15).

\section{Valoración patrimonial}

Definir qué consideramos valioso es un desafío, pues el valor patrimonial aparece como una condición subjetiva. Valorar es apreciar, otorgar cualidades específicas a algo o alguien. Además, conferir, o atribuir un sentido, más que un significado, es lo que realmente implica el hecho de valorar. Toda acción de valorar es una acción cultural; cultura es todo hacer humano "que está fundamentada en una selección demarcada previamente con un conocimiento que instituye unos supuestos determinados sobre las cuales se elige" (Frondizi, cit. en Alarcón, 2012, p. 4). "El valorar los bienes culturales se aplica tanto en el ámbito de las ideas, costumbres, tradiciones, folklore, etc., es decir, lo intangible o impalpable, como también en las manifestaciones materiales de la cultura, como son los objetos de arte, arquitectura, artesanía, etc., denominado tangible. La valoración del patrimonio cultural se remite entonces a criterios históricos, estéticos y simbólicos que fluctúan a través del tiempo de manera diversa y según la categoría de los bienes" (Alarcón, 2012, p.4).

\section{¿Cómo valoramos lo patrimoniable?}

El valor de cualquier bien patrimoniable vendría dado por una combinación de las valoraciones de los distintos individuos que se relacionan con este. Todo bien contiene ciertos elementos objetivos de valoración expresados en variables definidas y eventualmente parametrizadas (historia, formas constructivas, valores estéticos, etc.), y valores subjetivos, donde la asignación de valor responde a una serie de factores sociales, perceptivos o de significación social, no asociados a una dimensión técnica ni a estándares paramétricos de evaluación.

Se puede plantear un proceso metodológico riguroso y estructurado (Alarcón, 2012) basado en: 1) Identificación; 2) Valoración. A continuación, se describe cada punto. 


\section{Proceso de identificación de los bienes patrimoniables a nivel individual}

Prevalece un criterio amplio de inclusión, que permite revelar todo el universo de expresiones presentes. Los resultados se expresan en la construcción de un mapa virtual, con la determinación de componentes disciplinarios (arquitectura, arqueología, intangible, etc.).

\section{Valoración}

Se diseña un mecanismo de valoración multidisciplinario, que considera la percepción de los actores relacionados sobre un determinado bien, sitio u objeto patrimonial, para aproximarse a una medida de los siguientes valores:

- Valor económico.

- Valor histórico.

- Valor estético.

- Valor estético del espacio urbano.

- Valor simbólico.

- Valor social.

- Valor identitario.

- Valor territorial.

- Valor paisajístico.

- Valor afectivo.

Posible construcción de axiología patrimoniable: los lavaderos comunitarios del barrio El Paraíso-Observatorio de lo patrimoniable en el territorio Pardo Rubio.

\begin{tabular}{|c|c|c|c|}
\hline \multirow{3}{*}{$\begin{array}{c}\text { CONCEPTO } \\
\text { DE VALOR } \\
\text { (mirada desde la } \\
\text { filosofía) }\end{array}$} & \multirow[b]{2}{*}{ ENFOQUE } & Cultural & \\
\hline & & $\begin{array}{l}\text { Experiencia } \\
\text { vital }\end{array}$ & \\
\hline & $\begin{array}{l}\text { DEFINICIÓN } \\
\text { (relación } \\
\text { pensar - ser) }\end{array}$ & $\begin{array}{l}\text { Aspecto } \\
\text { praxiológico- } \\
\text { valorativo }\end{array}$ & $\begin{array}{l}\text { Interrelación } \\
\text { individuo- } \\
\text { sociedad }\end{array}$ \\
\hline
\end{tabular}


La perspectiva 1 de valoración desde la filosofía (concepto de valor) tiene como referente teórico el trabajo de Doris María Prieto sobre axiología contemporánea.

El concepto de valor en los lavaderos comunitarios se enfoca en la experiencia vital y en la cultura, y su definición se basa en el aspecto praxiológico-valorativo que se presenta en la interrelación individuo-sociedad.

\begin{tabular}{|c|c|c|c|c|c|}
\hline \multirow{6}{*}{$\begin{array}{l}\text { INDICADORES } \\
\text { ESTÉTICOS }\end{array}$} & \multirow{4}{*}{$\begin{array}{l}\text { Sistema } \\
\text { axiológico } \\
\text { en términos } \\
\text { subjetivos }\end{array}$} & \multirow{4}{*}{$\begin{array}{l}\text { Valoración } \\
\text { dimensiones } \\
\text { cualitativas }\end{array}$} & \multicolumn{3}{|c|}{ Construcción de relaciones } \\
\hline & & & \multicolumn{3}{|c|}{ Adaptaciones a variaciones de la vida urbana } \\
\hline & & & \multicolumn{3}{|c|}{$\begin{array}{l}\text { Experiencia múltiple y diversa de la vida social en } \\
\text { la ciudad }\end{array}$} \\
\hline & & & \multicolumn{3}{|c|}{$\begin{array}{l}\text { Significaciones que se construyen en la idea de } \\
\text { mundo como experiencia cultural }\end{array}$} \\
\hline & \multirow{2}{*}{$\begin{array}{l}\text { Dimensión } \\
\text { espacial en } \\
\text { la ciudad }\end{array}$} & \multirow{2}{*}{$\begin{array}{l}\text { Interacción } \\
\text { social, } \\
\text { cultural, } \\
\text { económica, } \\
\text { política }\end{array}$} & \multirow{2}{*}{$\begin{array}{l}\text { Las transfor- } \\
\text { maciones de } \\
\text { la diversidad } \\
\text { cultural }\end{array}$} & \multirow{2}{*}{$\begin{array}{l}\text { Campos } \\
\text { temáticos o } \\
\text { variables }\end{array}$} & $\begin{array}{l}\text { - Apropiación } \\
\text { y uso del espacio } \\
\text { público en } \\
\text { acontecimientos } \\
\text { (participación } \\
\text { colectiva) }\end{array}$ \\
\hline & & & & & $\begin{array}{l}\cdot \text { Formas de } \\
\text { apropiación } \\
\text { del paisaje } \\
\text { urbano }\end{array}$ \\
\hline
\end{tabular}


Desde la perspectiva de indicadores estéticos propuestos por Niño, se podría configurar para lo patrimoniable un sistema axiológico en términos subjetivos, con valoración de dimensiones cualitativas como: la construcción de relaciones, las adaptaciones a variaciones de la vida urbana, la experiencia múltiple y diversa de la vida social en la ciudad, las significaciones que se construyen en la idea de mundo como experiencia cultural.

Adicionalmente, la dimensión espacial en la ciudad involucra la interacción social, cultural, económica y política, y en ella se pueden ubicar como campos temáticos o variables para construcción de la matriz relacional: la apropiación y uso del espacio público en acontecimientos de participación colectiva y las formas de apropiación del paisaje urbano.

\begin{tabular}{|c|c|c|c|c|c|c|c|c|}
\hline Variables & Tema & Tiempo & Acciones & Actores & Problemas & Soluciones & $\begin{array}{l}\text { Mundo } \\
\text { Simbólico }\end{array}$ & $\begin{array}{c}\text { Estrategia } \\
\text { de vida }\end{array}$ \\
\hline $\begin{array}{l}\text { Apropiación y } \\
\text { uso del espacio } \\
\text { público en aconte- } \\
\text { cimientos } \\
\text { (participación } \\
\text { colectiva) }\end{array}$ & $\begin{array}{l}\text { Satisfacción } \\
\text { de limpieza }\end{array}$ & Variable & $\begin{array}{l}\text { Lavar } \\
\text { Conversar } \\
\text { Congregar }\end{array}$ & $\begin{array}{l}\text { Mujeres } \\
\text { Hombres } \\
\text { Niños }\end{array}$ & $\begin{array}{l}\text { Carencia } \\
\text { de red } \\
\text { servicios } \\
\text { públicos }\end{array}$ & $\begin{array}{l}\text { Espacio de } \\
\text { uso colec- } \\
\text { tivo }\end{array}$ & $\begin{array}{l}\text { Encuentro } \\
\text { Purificación } \\
\text { Cooperación }\end{array}$ & $\begin{array}{l}\text { Infraes- } \\
\text { tructura } \\
\text { básica } \\
\text { comunal }\end{array}$ \\
\hline $\begin{array}{l}\text { Formas de } \\
\text { apropiación del } \\
\text { paisaje urbano }\end{array}$ & $\begin{array}{l}\text { Lugar de } \\
\text { lavaderos }\end{array}$ & $\begin{array}{l}\text { Lavaderos } \\
\text { físicos } \\
\text { instalalados } \\
\text { permanen- } \\
\text { temente }\end{array}$ & $\begin{array}{l}\text { Construcción } \\
\text { con propios } \\
\text { medios }\end{array}$ & $\begin{array}{l}\text { Comuni- } \\
\text { dad }\end{array}$ & $\begin{array}{l}\text { Recursos } \\
\text { limitados }\end{array}$ & $\begin{array}{l}\text { Uso } \\
\text { colectivo }\end{array}$ & Colaboración & \\
\hline
\end{tabular}

La perspectiva de valoración con matriz holística relacional tiene como referente teórico el trabajo de Raúl Niño sobre indicadores estéticos de cultura urbana. Se crea la matriz con dos variables, a las cuales se pueden asignar relaciones en diferentes campos.

La primera variable Apropiación y uso del espacio público en acontecimientos (participación colectiva), tiene como tema la satisfacción de limpieza; el tiempo en el que se desarrolla la participación colectiva es variable, en torno a esta participación se desarrollan acciones como lavar, conversar, congregar. Los actores son mujeres y niños, los cuales resuelven mediante los lavaderos comunales la carencia de red 
de servicios públicos, configurándose de esta manera una estrategia de vida desde lo comunal. El aspecto simbólico gira en torno al encuentro y la purificación.

La segunda variable, Formas de apropiación del paisaje urbano, tiene como tema el lugar de los lavaderos; el tiempo en el que se desarrolla es permanente, considerando la infraestructura física de los lavaderos. Las acciones corresponden a las que se desarrollaron para lograr la construcción del lugar. Los actores están representados por la comunidad, los cuales resuelven mediante los lavaderos comunales la carencia individual y los recursos limitados, configurándose de esta manera una estrategia de vida desde la cooperación y la colaboración. El aspecto simbólico gira en torno a la unidad como fuerza.

\begin{tabular}{|c|c|c|c|}
\hline \multicolumn{4}{|c|}{ Valoración patrimonial / lavaderos } \\
\hline \multirow{7}{*}{$\begin{array}{l}\text { VALORACIÓN } \\
\text { PATRIMONIAL }\end{array}$} & $\begin{array}{l}\text { Elementos objetivos } \\
\text { de valoración }\end{array}$ & $\begin{array}{l}\text { Variables definidas y } \\
\text { eventualmente para- } \\
\text { metrizadas }\end{array}$ & $\begin{array}{l}\text { Historia: trayectoria del lugar } \\
\text { de lavaderos en el barrio }\end{array}$ \\
\hline & Valores subjetivos & $\begin{array}{l}\text { No asociados a una } \\
\text { dimensión técnica ni a } \\
\text { estándares paramétri- } \\
\text { cos de evaluación }\end{array}$ & $\begin{array}{l}\text { Factores de significación } \\
\text { social: lugar de encuentro y } \\
\text { colectividad }\end{array}$ \\
\hline & & \multicolumn{2}{|l|}{ Valor histórico } \\
\hline & & \multicolumn{2}{|l|}{ Valor simbólico } \\
\hline & Valoración & \multicolumn{2}{|l|}{ Valor social } \\
\hline & & \multicolumn{2}{|l|}{ Valor identitario } \\
\hline & & \multicolumn{2}{|l|}{ Valor afectivo } \\
\hline
\end{tabular}


La perspectiva de valoración desde lo patrimonial, tiene como referente teórico la valoración tradicional de los bienes patrimoniales. Para el caso de los lavaderos comunitarios se identifica como elemento objetivo de valoración la variable historia, y como valores subjetivos están los factores de significación social.

El conjunto axiológico para los lavaderos lo componen: el valor histórico (la trayectoria de los lavaderos en el tiempo-espacio del barrio), el valor simbólico (en torno a la actividad), el valor social (la importancia del lugar para la comunidad), el valor identitario (por la construcción colectiva del lugar) y el valor afectivo.

\section{Conclusiones}

En el estudio de lo patrimoniable es la estética la que conduce al significado, más allá de querer demostrar hechos.

Patrimoniable es un concepto clara e intencionalmente "borroso", con todas las potencialidades que esto conlleva en términos de capacidad de ajustarse a la realidad de cada contexto.

A partir del contexto específico, investigar lo patrimoniable implica dar respuesta a una interesante cuestión relacionada con la polisemia cultural. El contexto no representa un valor en sí mismo, sino que encarna una referencia dinámica, para un determinado sistema de creencias, expectativas o esperanzas, conocimientos o criterios de valoración discordantes. 
Indagar lo patrimoniable en el hábitat popular plantea preguntas asociadas con los lugares de la memoria y la memoria del lugar, y las formas de resistencia en el territorio de la postmetropoli. ¿Cómo se produce el valor del hábitat popular? ¿Cómo se difunde y deposita? Las respuestas y la producción de sentido les pertenecen a la comunidad local, ya que se componen de materialidad del espacio, percepciones, evocaciones, sensibilidad estética o moral, sentimientos, emociones, afectividad, espiritualidad, ideologías y transacciones metafóricas.

La incertidumbre asociada a la valoración de lo patrimoniable es igual de estimulante al tratamiento de la incertidumbre en matemática. En dicho campo de conocimiento, apropiarse y procesar expresiones lingüísticas que definan de forma muy descriptiva reglas o valores ha requerido quebrantar la lógica convencional y alcanzar una lógica difusa, produciendo nuevos conocimientos prácticamente útiles.

\section{REFERENCIAS BIBLIOGRÁFICAS}

Alarcón, M. (2012). Valoración del patrimonio cultural material. La Patria, Revista Dominical. Recuperado de http://lapatriaenlinea.com/?nota=106869

Andrade, Pérez M. (2013). ¿A quién y qué representa la lista representativa del patrimonio cultural inmaterial de la nación en Colombia? Boletín de Antropología, 28(46), 53-78.

Bauman, Z. (2009). La postmodernidad y sus descontentos. Madrid: Akal.

Baldacci, V. (2015). Tre diverse concezioni del patrimonio culturale. Cahiers d'études italiennes, 18, 47-59. Doi: 10.4000/cei.1518. Recuperado de https://journals.openedition.org/cei/1518\#text

Cacciari, M. (2010). La Ciudad. Barcelona: Gustavo Gili.

Capel, H. (2014). El patrimonio: la construcción del pasado y del futuro. Barcelona: Ed. El Serbal.

Congreso de Colombia (7 de agosto de 1997). Artículo 4 [Título II]. Ley General de Cultura [Ley 397 de 1997]. DO: 43 102. Recuperado de http://www.sinic.gov.co/SINIC/Sipa_Conceptos_Comite_Tecnico/ley\%20397\%20de\%201997.pdf 
Congreso de Colombia (12 de marzo de 2008). Por la cual se modifica y adiciona la Ley 397 de 1997 [Ley 1185 de 2008]. DO: 46 929. http://www.mincultura.gov.co/ministerio/oficinas-y-grupos/oficina\%20 asesora\%20de\%20planeacion/Documents/Ley_1185-2008.pdf

Constitución Política de Colombia [Const.] (1991). Artículos 8, 63, 72, 82, 95, 101, 102, 313, 332 y 333. Colombia: Legis.

Fabelo, C.J. (1989). Práctica, conocimiento y valoración. La Habana: Ciencias Sociales.

Fracasso, L. (2016). Lo "patrimoniable": utopías concretas, prácticas artísticas y hábitat popular. Actas del XIV Coloquio Internacional de Geocrítica: Las utopías y la construcción de la sociedad del futuro. Barcelona, España.

Gálvez Mora, I. (2008). La función utópica en Ernst Bloch [tesis de posgrado]. Recuperado de http://www. posgrado.unam.mx/filosofia/wp-content/uploads/2018/09/04galv.pdf

González Morcillo, C. (s.f.). Lógica difusa. Una introducción práctica. Técnicas de Softcomputing. Recuperado de http://www.esi.uclm.es/www/cglez/downloads/docencia/2011_Softcomputing/LogicaDifusa.pdf

Gómez Redondo, Carmen (2012) "Patrimonio e identidad: La educación patrimonial como vínculo entre individuo y entorno" en Comunicaciones del I Congreso Internacional de Educación Patrimonial. Mirando a Europa. Madrid del 15 al 18 de octubre 2012. Ministerio de Educación, cultura y deporteObservatorio de Educación Patrimonial de España.

González, R. F., y Valdés, C. H. (1994). Psicología humanista. Actualidad y desarrollo. La Habana: Ciencias Sociales.

Hernández García, J. (2005). Participación y hábitat ¿sueño posible o relación no deseada? Revista INVI, noviembre, año/vol. 20, n. 055, UNiversidad de Chile, Santiago de Chile pp. 48-81.

Leone, Massimo (a cura di) (2008). "La cittá come testo. Scritture e riscritture urbane. Atti del Convegno Internazionale Università di Torino - Facoltà di Lettere e Filosofia" 19-20 maggio 2008 Lexia. Rivista di Semiotica. 01/02/2008

Levitas, Ruth. La esperanza utópica: Ernst Bloch y la reivindicación del futuro 2008. En: Revista Mundo Siglo XXI№ 12. México. Recuoerado de http://www.mundosigloxxi.ciecas.ipn.mx/pdf/v03/12/02.pdf

McNiff, S. (1998) Art-based Research, Jessica Kingsley Publishers. 
Magnaghi, A. (1998). II territorio degli abitanti: società locali e autosostenibilità. Milano: Dunod.

Mariñelarena, P. (2015). Estética urbana. Memoria, arte y significados [tesis doctoral]. Universidad Nacional de la Plata, Argentina. Recuperado de http://hdl.handle.net/10915/50834

Martín Barbero, J. (1998). ¿Qué entendemos por patrimonio? Recuperado de http://convenioandresbello. org/somos_patrimonio/historia/

Martín Barbero, J. (2008). Patrimonio Mundial. Recuperado de https://www.youtube.com/watch?v=iOiu448OlfM

Martín Barbero, J. (2010). La reinvención patrimonial de América Latina. [Archivo de video] Recuperado de http://www.gestioncultural.org/entrevistas_videos.php?id_evento=187976

Martinez Contreras, Javier. Las huellas de lo oscuro: estética y filosofía en Ernst Bloch, Editorial San Esteban, 2004.

Ministerio de Cultura de Colombia (10 de marzo de 2009). Por el cual se reglamentan parcialmente las Leyes 814 de 2003 y 397 de 1997 [Decreto 763 de 2009] DO: 47 287. Recuperado de http://www.mincultura. gov.co/prensa/noticias/Documents/Patrimonio/Decreto\%20763\%202009.pdf

Ministerio de Cultura de Colombia (6 de agosto de 2009). Por el cual se reglamenta parcialmente la Ley 397 de 1997[Decreto 2941 de 2009]. DO: DIARIO OFICIAL. AÑO CXLIV. N. 47433. 6, AGOSTO, 2009. PÁG. 73. Recuperado de http://www.suin-juriscol.gov.co/viewDocument.asp?ruta=Decretos/1503266

Ministerio de Cultura de Colombia (24 de febrero de 2010). Por la cual se desarrollan algunos aspectos técnicos relativos al patrimonio cultural de la Nación. [Resolución 330 de 2010]. DO: 47 638. Recuperado de http://www.mincultura.gov.co/areas/patrimonio/patrimonio-cultural-en-Colombia/lista-indicativade-candidatos-a-bien-de-interes-cultural/Documents/Resoluci\%C3\%B3n\%20N\%C3\%BAmero\%20 0983\%20Mayo\%2020\%20de\%202010.pdf 
Nora, P. (1986 ed. 2009). Los lugares de la memoria. Santiago : LOM.

Niño, R. (2006). Indicadores estéticos de cultura urbana. Bogotá: Pontificia Universidad Javeriana.

Olagree, T. (1995). Valor y valoración. En: Enciclopedia de Bioética [CD ROM].

Prieto Ramírez, D. M. (2002). Problemas contemporáneos de la Axiología. Humanidades Médicas, 2(3), versión on line

Proponen declarar villas miseria patrimonio de la humanidad (15/05/2018). El Clarín. Recuperado dehttps://www. clarin.com/mundo/proponen-declarar-villas-miseria-patrimonio-humanidad_0_SJQVrw_Az.html

Sánchez Ruiz Jorge E. (2009) El hábitat no es una cosa en Echeverría R. María Clara; Yory Carlos Mario; Sánchez R. Jorge E.; Gutiérrez Felipe; Zuleta R. Fabián Beethoven; Muñoz Edilson, (2009). ¿Qué es el hábitat? : las preguntas por el hábitat. - Medellín, Col. : Escuela del Hábitat CEHAP, Facultad de Arquitectura, Universidad Nacional de Colombia sede Medellín, 2009.

SINIC Sistema Nacional de Información Cultural http://www.sinic.gov.co/sinic/

Toledo Castellanos, R. (2017) El arte y el mundo ordinario en Cuaderno de Musica, Artes Visuales y Escenicas / Volumen 12 - Número 2 julio - diciembre de 2017 / ISSN 1794-6670/ Bogotá, D.C., Colombia / pp. 9-12.

Turco, A. (2010). Configurazioni della territorialità. Milano, Italy: Franco Angeli.

UNESCO (2003). Patrimonio Cultural Inmaterial. Recuperado de https://ich.unesco.org/doc/src/01852-ES.pdf

UNESCO (2016). La UNESCO en México y la Secretaría de Desarrollo Social de la CDMX celebran el foro 'La periferia como Patrimonio Cultural Urbano'. Servicio de prensa. (17 de agosto de 2016). Recuperado de http://www.unesco.org/new/es/media-services/single-view/news/ la_unesco_en_mexico_y_la_secretaria_de_desarrollo_social_d/

UNESCO (s.f.) Proteger el patrimonio y fomentar la creatividad. Recuperado de https://es.unesco.org/ themes/proteger-patrimonio-y-fomentar-creatividad

Wittgenstein L. (2008). Investigaciones Filosóficas (Trad. A. García Suárez y U. Moulines). Barcelona: Crítica.

Zorshantov, V. F., y Grechanii, V. V. (1985). El hombre como objeto del conocimiento filosófico. La Habana: Pueblo y educación. 